\title{
Metas para a Taxa de Câmbio, Agregados Monetários e Inflação
}

\author{
Exchange Rate, Monetary, and Inflation Targets
}

HELDER FERREIRA DE MENDONÇA*

RESUMO: Desde o início da Teoria Quantitativa da Moeda, por David Hume, a relação entre moeda e nível de preços foi analisada por economistas monetários. Atualmente, a busca por estabilidade de preços levou os formuladores de políticas a adotarem um dos três regimes monetários: taxa de câmbio fixa, metas monetárias ou metas de inflação. O presente artigo faz uma análise comparativa entre essas possibilidades, destacando as vantagens e desvantagens de cada regime monetário.

PALAVRAS-CHAVE: Metas; taxa de câmbio; agregados monetários; inflação.

ABSTRACT: Since the beginning of the Quantitative Theory of Money by David Hume, the relation between money and price level has been analyzed by monetary economists. Nowadays the search for price stability has induced the policymakers to adopt one of three monetary regimes: fixed exchange rate, monetary targeting, or inflation targeting. The present paper makes a comparative analysis among these possibilities highlighting the advantages and disadvantages that belong to each monetary regime.

KEYWORDS: Targets; Exchange rate; monetary aggregates; inflation.

JEL Classification: E52; E58.

\section{INTRODUÇÃO}

Desde os primórdios da Teoria Quantitativa da Moeda com David Hume, a relação entre moeda e nível de preços passou a ser objeto de análise para economistas monetários. Ao longo dos séculos XIX e XX, diversos regimes monetários foram utilizados na tentativa de disciplinar o comportamento dos preços. Outrora, o regime monetário mais utilizado foi o padrão ouro, mas, devido à derrocada do

\footnotetext{
* Professor do Departamento de Economia da Universidade Federal Fluminense. E-mail: helderfm@ hotmail.com; ORCID 0000-0003-1465-1755.
} 
sistema de Bretton Woods ${ }^{1}$ no início dos anos 70, a aplicação desse regime entrou em desuso. $\mathrm{Na}$ busca de um novo regime monetário capaz de estabilizar preços, a utilização do controle de agregados monetários tornou-se uma prática comum em diversos países. Todavia, devido ao insucesso da monitorização dos agregados monetários para a estabilização de preços, vários países, sobretudo os emergentes, passaram a empregar variantes de um regime de câmbio fixo (crawling peg, currency board, plena dolarização etc.).

Nos anos 90, um novo regime monetário, com base nas idéias originais de Marshall (1887) e Wicksell (1898), tem se difundido com relativa velocidade tratase do emprego de metas para a inflação. O motivo para a rápida propagação dessa estratégia para a política monetária é a idéia desenvolvida a partir da segunda metade da década de 80 de que bancos centrais devem ser independentes e que possuem como meta natural a busca da estabilidade de preços.

O presente artigo tem por objetivo fazer uma análise comparativa do emprego de metas para os regimes monetários mais utilizados salientando-se as vantagens e desvantagens associadas a cada regime ${ }^{2}$. O estudo apresenta-se estruturado da seguinte forma: a segunda seção discute o comportamento da taxa de câmbio como âncora nominal dando-se atenção especial à estrutura de um currency board; a terceira analisa o papel das metas monetárias como estabilizadora de preços na economia; a quarta examina o caso do uso de metas para a inflação; por último, é apresentada a conclusão dos pontos levantados ao longo do artigo.

\section{METAS PARA A TAXA DE CÂMBIO}

A utilização da taxa de câmbio como âncora nominal consiste em um regime de política monetária bastante antigo. Um dos mais conhecidos exemplos foi o padrão ouro ${ }^{3}$. O padrão ouro foi um sistema monetário que vigorou de 1870 até a Primeira Guerra Mundial, no qual um país estabelecia o ouro como moeda ou fixava uma taxa de conversão da moeda em ouro, o que, por conseguinte, implicava taxas nominais de câmbio fixas entre os países ${ }^{4}$.

Deve-se salientar que o padrão ouro impunha limites ao governo, pois eram emitidos títulos da dívida com o compromisso de convertê-los em ouro. Destarte, os agentes estimavam a capacidade de solvência do governo tendo por base o nível

\footnotetext{
${ }^{1}$ Versão modificada do padrão ouro que passou a vigorar após a Segunda Guerra Mundial.

${ }^{2} \mathrm{~A}$ análise aqui realizada concentra-se no aspecto monetário, as recentes discussões sobre a "teoria fiscal da determinação do nível de preços” não são consideradas. A principal justificativa para a não inclusão neste estudo deriva do fato de que as evidências empíricas não se mostram robustas. Para uma leitura sobre a "teoria fiscal da determinação do nível de preços", ver McCallum (1999).

${ }^{3}$ Para uma leitura sobre a relação padrão ouro e estabilidade de preços ver Barro (1993); para uma análise teórica e histórica ver Schwartz (1987) e Bordo (1993).

${ }^{4}$ De 1944 a 1971, as relações monetárias internacionais entre as nações industrializadas foram determinadas pelo sistema de Bretton Woods (padrão câmbio-ouro) — as moedas eram conversíveis em dólares, e as reservas em dólares eram conversíveis em ouro pelos EUA a um preço fixo (US\$ 35 a onça).
} 
de reservas. Como, na prática, nenhum governo mantinha a totalidade de suas reservas em ouro, a credibilidade dos títulos da dívida dependia da capacidade de arrecadação. Logo, o elemento-chave para garantir a conversibilidade era a condução da política fiscal. Ou seja, um equilíbrio orçamentário seria fundamental para que os agentes formassem suas expectativas de forma que a solvência da dívida emitida fosse crível e impedisse o uso de uma política financeira inflacionária.

Uma versão moderna do padrão ouro consiste no uso de um currency board. ${ }^{5}$ Nessa estrutura, a moeda doméstica tem o valor fixado em termos da moeda do país âncora, tendo sua oferta ressalvada por ativos em moeda estrangeira.

"The rate of exchange between a board's currency and its reserve currency is fixed by law and enforced by the board's obligation to trade its currency for the reserve currency at the prescribed rate of exchange. A currency board guarantees its commitment to maintain its fixed rate of exchange by backing its liabilities with a prescribed amount of foreign exchange assets, mostly denominated in its reserve currency." (Kopcke, 1999, p. 22)

Um dos principais motivos para a adoção de currency board por economias emergentes advém do fato de que essa estratégia estabelece uma autoridade monetária que é independente do governo e que segue uma política monetária conservadora (avessa à inflação), o que, por conseguinte, proporciona um aumento na confiança dos ativos e na moeda doméstica.

As principais vantagens associadas à adoção de um currency board podem ser sumariadas em quatro pontos básicos (Mishkin \& Savastano, 2000): i) ajuda a evitar a aceleração inflacionária por meio da restrição imposta aos preços de bens comercializáveis produzidos domesticamente, atenua o componente inercial da inflação que alimenta salários e preços não-comercializáveis, e provoca a convergência das expectativas inflacionárias tendo por referência o país âncora; ii) reduz o custo de captação de fundos para o governo e setor privado devido à eliminação do componente de risco sobre a moeda proveniente da taxa de juros doméstica; iii) cria um mecanismo de ajuste automático para a oferta de moeda que ajuda a atenuar o problema de inconsistência temporal da política monetária ${ }^{6}$; e iv) são facilmente compreendidos pelo público.

As duas mais importantes decisões para a implementação de um currency board referem-se à escolha da moeda de reserva e à taxa de câmbio. Para o primeiro aspecto, a moeda estrangeira selecionada deve ser forte o suficiente para transferir sua

\footnotetext{
${ }^{5} \mathrm{O}$ currency board e a plena dolarização representam os dois principais regimes de fixação rígida para a política monetária. Um currency board restringe a taxa de câmbio à necessidade de uma reserva legal e retira a condução da política monetária das mãos do banco central ou do governo. A plena dolarização, além das características mencionadas para o currency board, implica a substituição da moeda doméstica pela moeda legal do país selecionado.

${ }^{6}$ Uma queda (elevação) na demanda por ativos domésticos produz um fluxo de saída (entrada) de capitais que leva a uma elevação (redução) da taxa de juros sem criar pressões sobre a paridade anunciada.
} 
credibilidade à moeda doméstica. Nesse sentido, as duas moedas mais utilizadas como moeda de reserva têm sido o dólar americano e o marco alemão (ver tabela 1).

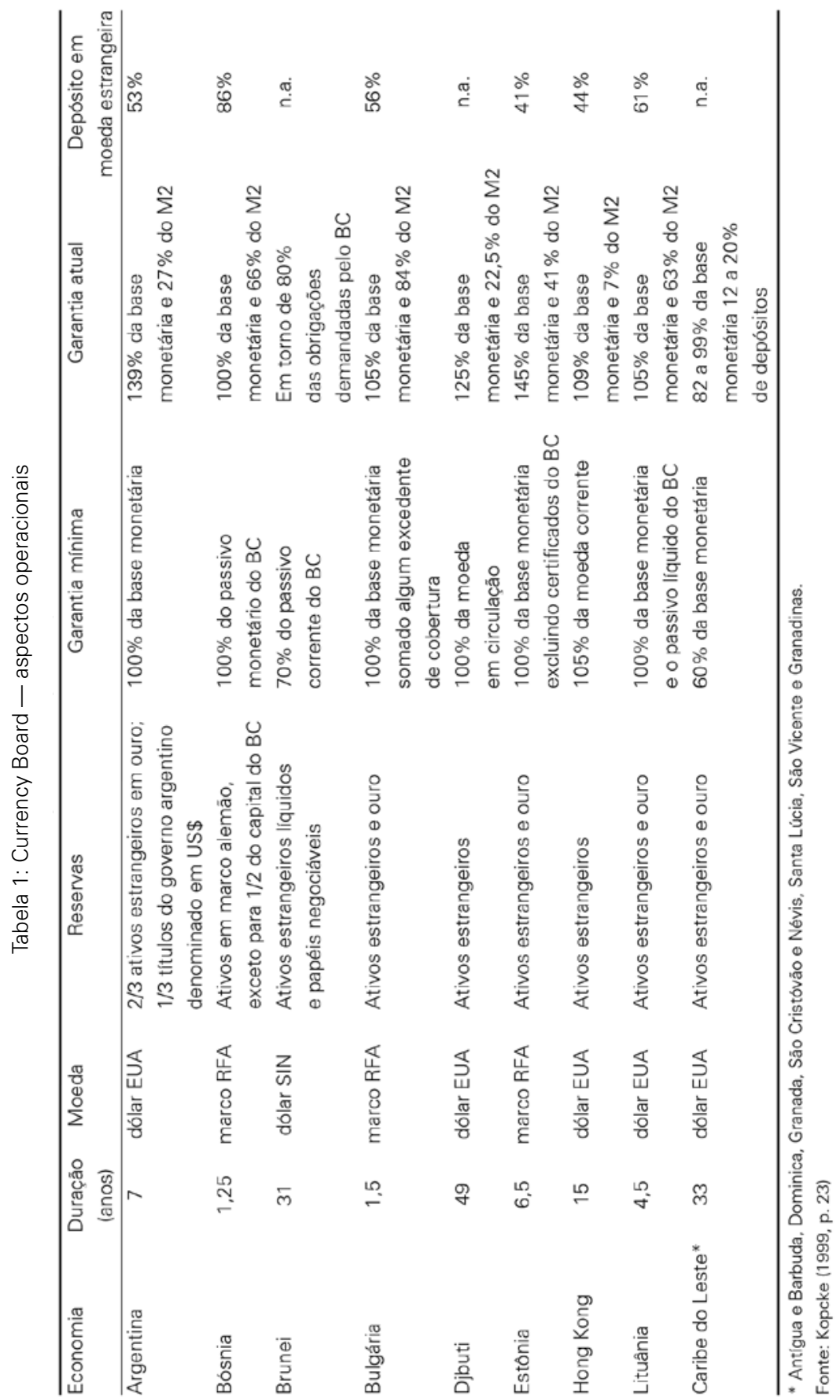


Do ponto de vista teórico, um país que varia a oferta monetária em função de suas reservas em moeda estrangeira adota um regime monetário que regula de forma automática o nível de preços e o crescimento da atividade econômica. Por exemplo, quando os preços dos fatores de produção, bens e serviços de um país que adotou um currency board aumentam de forma mais rápida do que em outros países, isso implica uma deterioração na balança comercial, o que por sua vez acarreta uma desaceleração na taxa de acumulação de reservas. Por outro lado, quando os preços caem em relação a outros países, tende a ocorrer uma aceleração das reservas estrangeiras, base monetária e crédito, tendo por resultado uma queda na taxa de juros e um aumento na demanda. Ou seja, o sucesso da adoção de um currency board depende em grande medida da velocidade do ajuste dos preços (inclusive contratos financeiros) frente às forças de oferta e demanda.

Ademais, o êxito de um currency board está atrelado à estabilidade do sistema financeiro. Quando comerciantes e investidores se preocupam com a capacidade de solvência do sistema financeiro, ou quando o endividamento do governo aumenta de forma muito rápida comparado ao crescimento do produto doméstico, o regime pode entrar em colapso devido às dúvidas que emergem quanto à possibilidade de o governo arcar com os ativos denominados em moeda estrangeira. Em suma, o sucesso na introdução de currency board demanda um sistema financeiro saudável, uma autoridade fiscal responsável e um mercado de capitais com razoável eficiência.

Embora um currency board possa limitar a taxa de inflação da economia, ele não garante uma baixa taxa de inflação ou a mesma taxa de inflação do país cuja moeda foi adotada como âncora.

"When the mix of goods and services that the developing economy produces and consumes is not the same as that for the developed country, the price indexes for the two economies can change at different rates. This potential for divergence increases as more of the two economies' products are priced in different markets. Differences in the growth of productivity between the two economies also can cause their rates of inflation to differ. Productivity in a developed country might not increase as rapidly as in a developing economy that gradually absorbs the best available technology. In these circumstances, when the exchange rate between the two economies' currencies is fixed, the prices of the developing economy's outputs that do not compete closely with those of the developed country will tend to inflate more rapidly.” (Kopcke, 1999, p. 27)

É importante ressaltar que o fato de um currency board fixar uma taxa de câmbio para a moeda implica diversas limitações ao banco central (BC) quanto à capacidade de alterar a oferta monetária. Atividades como: emprestador de última instância, operações de open market, leilão de depósitos, ou outras ações que alterem a oferta monetária; sofrem fortes restrições, ficando na maioria das vezes limi- 
tadas à aquisição de moeda estrangeira destinada à formação de reservas 7 . Portanto, tal estrutura não permite o uso da política monetária como capaz de determinar de forma independente o nível de emprego, preços, taxa de juros, oferta de moeda, volume de crédito e fluxo de capital.

Além das desvantagens supracitadas, observa-se que há a perda na possibilidade de uso da política monetária frente a choques sobre a economia doméstica. Esse é um ponto importante, pois num cenário em que preços domésticos e salários se ajustam de forma lenta, mercados são incompletos e há uma flexibilidade fiscal abaixo do ideal, o impacto de choques sobre a economia provoca grandes variações sobre o lado real da economia (investimento, produto e emprego), que não podem ser neutralizadas pela ação de uma política monetária ativa.

Soma-se às observações realizadas o fato de que um currency board apresenta um controle imperfeito sobre a moeda e o volume de crédito da economia, uma vez que o sistema financeiro desenvolve depósitos bancários que não são limitados à oferta de moeda condicionada ao nível de reservas. Outrossim, as empresas também podem gerenciar o fluxo de capital provindo do exterior levando em consideração a conta corrente do país. Assim sendo, o regime em consideração não é capaz de disciplinar os gastos governamentais, sobretudo quando o governo pode realizar venda de ativos ou pode conduzir a política fiscal por meio de interferências sobre instituições financeiras.

O currency board não deve ser entendido como uma estrutura que deve ser utilizada por tempo indeterminado ${ }^{8}$. Na verdade, a utilização de uma taxa de câmbio fixo pode ser um bom começo para a busca da estabilização de uma economia, entretanto, a redução na responsabilidade do $\mathrm{BC}$ sobre a política monetária deve ser provisória. A autoridade monetária deve se preparar para reassumir suas funções e implementar uma política monetária que seja capaz de manter a estabilidade da economia de forma crível (Kopcke, 1999). Nesse sentido, a adoção de uma taxa de câmbio fixo ou um crawling peg pode ser um primeiro passo após uma economia abandonar o currency board 9 .

Quando da adoção de um regime de câmbio fixo, a existência de um volume

\footnotetext{
${ }^{7} \mathrm{O}$ empréstimo do banco central ao sistema financeiro em um momento de crise desencadeia o temor de uma explosão inflacionária e provoca fortes pressões para depreciação da taxa de câmbio.

${ }^{8}$ A principal desvantagem de um currency board com relação plena dolarização refere-se ao fato de não ser eliminada por completo a possibilidade de uma desvalorização. Ou seja, uma plena dolarização afasta o perigo de ataques especulativos e implica menores taxas de juros desde que não haja incerteza sobre o valor da moeda que circula no país. É importante ressaltar que uma plena dolarização não garante que a taxa de juros convergirá para a que prevalece no país âncora. Na maioria das vezes, a taxa de juros doméstica incorpora uma taxa de risco que pode ser entendida como o risco do confisco de ativos pelo governo.

${ }^{9} \mathrm{O}$ uso de uma taxa de câmbio fixo permite maior flexibilidade para o $\mathrm{BC}$ no que se refere ao nível de reservas. Sob um regime de câmbio fixo, em lugar de um currency board, o BC pode realizar operações de open market e empréstimos aos bancos, mas não pode determinar suas próprias taxas de juros. No caso de uma redução das taxas de juros via compra de títulos domésticos pelo banco central, é provável que ocorra uma saída de capitais que compense a redução nos juros.
} 
suficiente de reservas, capaz de fazer com que a expectativa do público em relação à taxa de câmbio futura não se altere, representa a condição sine qua non para que a paridade estabelecida seja crível. Mesmo no caso de bandas cambiais ${ }^{10}$, as reservas desempenham papel importante. Pode-se dizer que as reservas funcionam como um indicador do nível de vulnerabilidade da economia. Se as reservas diminuem com grande velocidade, esse movimento sinaliza aos agentes uma possível mudança do regime cambial, fazendo com que a perda de reservas se acelere e a economia aumente sua exposição a ataques especulativos. Ou seja, o principal problema com esse regime é o fato de a economia que o adotou depender de um cenário internacional estável.

Um exemplo dessa situação é o sistema de bandas cambiais que vigorou no Brasil de junho de 1994 a janeiro de 1999. Enquanto o cenário macroeconômico internacional não apresentou grandes flutuações, os problemas advindos de uma menor potência da política monetária não foram percebidos. Contudo, após a crise asiática (outubro de 1997), o problema tornou-se evidente. Na tentativa de neutralizar os ataques especulativos contra a moeda doméstica, o BC elevou continuamente a taxa de juros doméstica para evitar a saída de capitais. Apesar desse recurso, o sistema mostrou-se insuficiente para garantir a manutenção do regime de bandas, tendo por conseqüência a mudança para um regime de câmbio flexível em janeiro de 199911.

De acordo com European Monetary Institute, a adoção de metas para a taxa de câmbio, taxa de juros ou produto para a economia são consideradas inadequadas para o objetivo da busca da estabilidade de preços.

"First, an exchange rate objective is not considered appropriate since, for an area potentially as large as the euro area, such an approach might be inconsistent with the internal goal of price stability. Second, the use of an interest rate as an intermediate target is not considered appropriate given difficulties in identifying the equilibrium real interest rate which would be consistent with price stability. Third, employing the growth rate of nominal GDP which can be viewed as consistent with price stability as an intermediate target would provide a clear nominal framework and would have the advantage of not being sensitive to shocks in the income velocity of money. However, nominal income would be difficult to control by the ESCB, could lead to misinterpretation of the ultimate goal of the ESCB, could be subject to substantial data revisions and might lead to an indeterminate price/volume division in the short run, thus creating

\footnotetext{
${ }^{10}$ Admite-se a flutuação da taxa de câmbio dentro de limites estabelecidos pela autoridade monetária.

11 Os resultados obtidos não foram satisfatórios, apesar de a inflação ter se mantido relativamente estável no período, os custos sociais não foram desprezíveis - houve aumento recorde da taxa de desemprego e o quadro fiscal ficou muito debilitado. A lição que se tira do caso brasileiro é que a adoção de um regime de câmbio fixo por si só não é capaz de desenvolver uma reputação que garanta a credibilidade necessária em períodos de crise.
} 
uncertainty about the inflation performance of the economy. Furthermore, the fact that nominal income targeting is not used at present in any EU Member State makes it inadvisable for the ESCB to adopt this strategy.” (EMI, 1997, p. 1, grifos meus)

Destarte, o debate recente sobre qual o melhor regime monetário a ser adotado concentra-se na escolha entre metas monetárias ou metas inflacionárias.

\section{METAS MONETÁRIAS}

Para muitos países ou blocos (EUA, Japão, UME etc.), a meta para a taxa de câmbio não se constitui uma opção de regime monetário, pois não há uma moeda que sirva de forma adequada como âncora nominal para essas economias. Nesse caso, uma das principais opções de regime monetário consiste na adoção de uma meta monetária.

Uma estratégia de metas monetárias para o controle da inflação compreende quatro elementos básicos (Mishkin \& Savastano, 2000):

i) confiança nas informações transmitidas por um agregado monetário para

condução da política monetária; ii) anúncio das metas para um agregado monetário capaz de guiar as expectativas inflacionárias do público; iii) criação de algum mecanismo de responsabilidade que elimine grandes e sistemáticos desvios da meta monetária; e iv) inexistência de dominância fiscal e presença de taxa de câmbio flexível.

Exemplos de países que obtiveram sucesso com o regime de metas monetárias nos anos 70 foram Alemanha e Suíça ${ }^{12}$. O êxito obtido por esses países é atribuído ao fato de que a estrutura utilizada foi diferente da proposta pela ortodoxia monetarista (regra rígida de expansão da oferta monetária), visto que foi possível fazer uso da política monetária como instrumento capaz de afetar a taxa de câmbio e o produto da economia. A principal característica dos países sobreditos é que o regime de meta monetária foi entendido como uma forma de comunicação da estratégia de longo termo da política monetária para o controle da inflação, cujo resultado acarretou um aumento na transparência da política monetária e da responsabilidade do BC.

As principais vantagens da meta monetária sobre a fixação da taxa de câmbio podem ser sumariadas em três pontos básicos: i) a capacidade do BC de escolher suas metas para inflação; ii) a possibilidade de a política monetária responder às

\footnotetext{
12 Os bons resultados obtidos por Alemanha e Suíça não podem ser generalizados. "The U.S. and the U.K., for example, attempeted to regulate the growth of money aggregates in the early 1980s and then quickly abandoned the policy after the aggregates went haywire. Financial innovation in each instance was the underlying culprit. Even in Germany, long considered a bastion of money targeting, there have been problems. Unstable movements in money demand have forced a retreat from strict money growth targeting” (Clarida, Gali \& Gertler, 1999, p. 49).
} 
flutuações do produto no curto termo e a choques externos; e iii) maior transparência da condução da política monetária, uma vez que são reportados em intervalos regulares de tempo o comportamento dos agregados monetários ao público.

Esquema 1

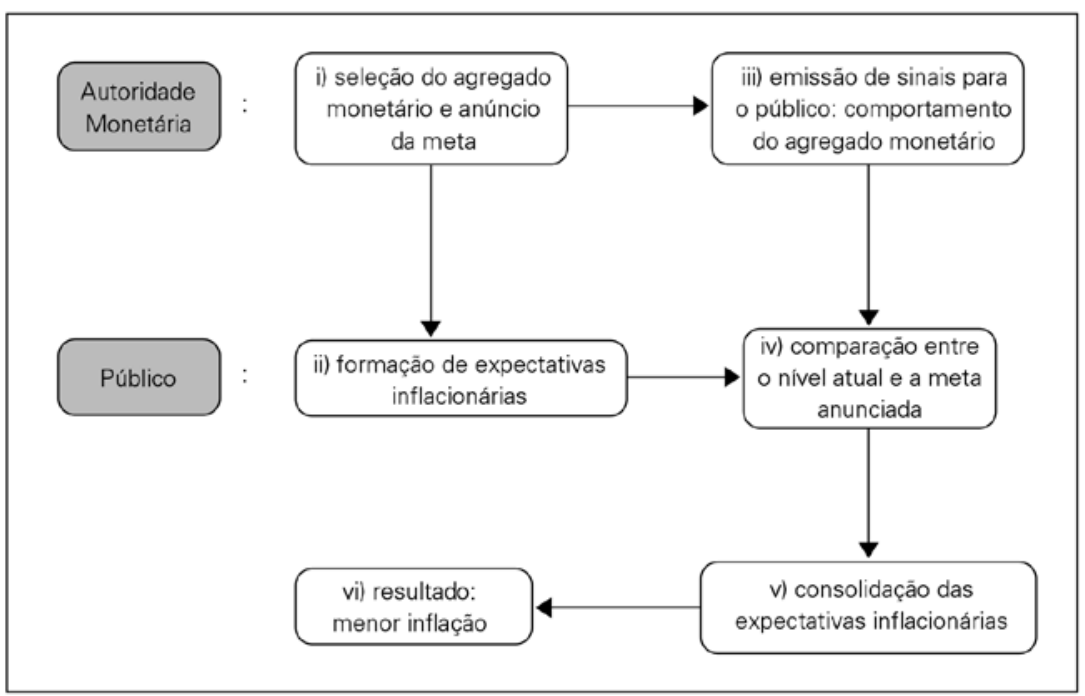

A estratégia de metas monetárias parte do pressuposto de que o BC torna-se mais comprometido com o objetivo de inflação baixa sendo capaz de atenuar o problema de inconsistência temporal da política monetária. O mecanismo para a busca de baixa inflação pode ser entendido da seguinte forma (ver esquema 1): i) em um primeiro momento, é anunciado o agregado monetário selecionado e sua respectiva meta; ii) esse agregado torna-se a principal fonte de sinais para o público na formação de expectativas sobre a inflação futura; iii) a autoridade monetária divulga informações sobre o comportamento do agregado monetário; iv) o público faz o cotejo entre a informação divulgada pelo BC e a meta anunciada; v) os sinais emitidos pela autoridade monetária ajudam a consolidar as expectativas inflacionárias do público; e vi) menor inflação é obtida.

Apesar das vantagens associadas à adoção de metas monetárias em relação à estratégia de fixar a taxa de câmbio, há dois problemas que devem ser considerados quando de sua adoção:

"[The first] If there is velocity instability, so that the relationship between the monetary aggregate and the goal variable is weak, then monetary aggregate targeting will nor work. The weak relationship implies that hitting the target will not produce the desired outcome on the goal variable and thus the monetary aggregate will no longer provide an adequate signal about the stance of monetary policy. Thus, monetary targeting will 
not help fix inflation expectations and be good guide for assessing the accountability of the central bank. (...) The second if is that the targeted monetary aggregate must be well controlled by the central bank. If not, the monetary aggregate may not provide as clear signals about the intentions of the policymakers and thereby make it harder to hold them accountable. Although narrow monetary aggregates are easily controlled by the central bank, it is far form clear that this is the case for broader monetary aggregates like M2 or M3.” (Mishkin, 1999, p. 13, grifo meu)

De acordo com Svensson (1999), existem dois tipos básicos de regimes de metas monetárias: o estrito (strict) - que corresponde a um exercício teórico que não é utilizado por nenhum $\mathrm{BC}^{13}$; e o pragmático (pragmatic) — que consiste na atual política implementada pelo Bundesbank.

Do ponto de vista teórico (assumindo-se a neutralidade da moeda), é esperado que a adoção de uma meta de crescimento monetário (estrita) é capaz de obter a taxa de inflação desejada no longo período; entretanto, no médio prazo, existe a possibilidade de emergir um conflito entre estabilizar a expansão monetária ou a inflação. Esse conflito é resultado da demora em ser percebido o efeito sobre a inflação decorrente de uma variação monetária, o que revela um trade-off potencial entre as duas variações. Esse trade-off torna-se evidente quando se adota um regime de meta inflacionária. A adoção dessa estratégia implica a minimização da variabilidade em torno da meta para a inflação, mas, por outro lado, estimula a variabilidade da taxa de expansão da oferta monetária. Em contrapartida, o uso de uma meta para expansão monetária apresenta menor variabilidade para o crescimento da oferta monetária. Não obstante, essa estrutura implica a possibilidade de haver considerável flutuação em torno da meta da inflação ${ }^{14}$.

Uma outra variante do regime de metas monetárias consiste na aplicação de metas monetárias pragmáticas. A principal diferença em relação ao caso anterior advém do fato de que é adotado, de forma concomitante à meta monetária, uma meta inflacionária ad hoc $c^{15}$. Além da Alemanha, um outro exemplo de metas monetárias pragmáticas é o caso europeu. O acordo de Maastricht, em seu artigo 105, estabelece como objetivo principal para o ESCB a manutenção da estabilidade de

\footnotetext{
${ }^{13}$ Uma meta de crescimento monetário estrita pode ser representada pela minimização de uma função de perda que corresponde ao desvio ao quadrado entre o crescimento monetário observado e o planejado, isto é, $\mathrm{L}_{\mathrm{t}}=1 / 2\left(\Delta \mathrm{m}_{\mathrm{t}}-\Delta \mathrm{m}^{*}\right)^{2}$, onde $\Delta \mathrm{m}_{\mathrm{t}}=$ crescimento monetário; $\Delta \mathrm{m}^{*}=$ meta de crescimento monetário.

${ }^{14}$ Svensson (1999) destaca a existência de evidências empíricas que corroboram a existência do tradeoff supracitado. Essa é uma observação importante, pois sinaliza a dificuldade do uso do regime de metas monetárias estritas como uma âncora nominal capaz de estabilizar a inflação.

${ }^{15}$ No caso alemão, entre 1996 e 1998, foi admitido como meta para a inflação o intervalo entre 1,5\% a $2 \%$. Vale destacar que, na existência do conflito entre a estabilização da inflação para a meta inflacionária e a estabilização do crescimento monetário para a meta monetária, o Bundesbank tem dado prioridade à meta inflacionária, o que implica uma aproximação do regime de metas monetárias pragmáticas ao caso de metas inflacionárias.
} 
preços. Após o encontro de 13 de outubro de 1998, o ECB anunciou três elementos básicos para a estratégia da política monetária: i) uma definição quantitativa do objetivo primário (estabilidade de preços) da política monetária única; ii) uma regra monetária com referência à expansão dos agregados monetários; e iii) o anúncio de um intervalo que reflita a perspectiva do comportamento futuro dos preços.

O ponto de distinção entre o regime de metas inflacionárias e o de metas monetárias pragmáticas consiste na comunicação da autoridade monetária com os agentes econômicos. No caso do Bundesbank, a comunicação é feita sob uma estrutura de metas monetárias com a existência de explicações para o caso de descumprimento das metas estabelecidas.

"Inflation targeting and pragmatic monetary targeting appear to be similar with regard to the loss function and the framework for policy decisions. The difference regards communication and transparency. Under inflation targeting, communication is direct and to the point. The rhetoric is consistent with the framework for policy decisions. Words match actions, and vice versa. Inflation targeting is 'inflation targeting in the open', whereas pragmatic monetary targeting is 'inflation targeting in disguise'. Under pragmatic monetary targeting, the communication and discussion is, deliberately, mainly focused on irrelevant misses of the monetary targets and the ad hoc explanations thereof. In practice, the choice between inflation targeting and pragmatic monetary targeting is a choice between transparency and nontransparency." (Svensson, 1999, p. 11, grifos meus)

\section{METAS INFLACIONÁRIAS}

O regime de metas inflacionárias é caracterizado pelo anúncio oficial de uma banda para a flutuação da taxa de inflação e pelo reconhecimento explícito de que o principal objetivo da política monetária deve ser a manutenção de uma taxa de inflação baixa e estável. Ou seja, tal estratégia para a política monetária tem como princípio a neutralidade da moeda no longo prazo. Outrossim, é assumido que as metas de inflação aumentam a comunicação com o público sobre os planos e objetivos das autoridades monetárias, tendo por conseqüência um aumento da responsabilidade do $\mathrm{BC}$ na busca das metas prenunciadas.

A meta inflacionária é uma estratégia de política monetária que envolve cinco elementos básicos (Mishkin \& Savastano, 2000): i) anúncio público em números da meta de médio prazo para a inflação; ii) compromisso institucional para estabilidade de preços como objetivo prioritário para a política monetária; iii) informação do comportamento das principais variáveis responsáveis pela estratégia; iv) transparência da estratégia de política monetária (elemento central para comunicação com o público e planejamento dos mercados); e v) criação de mecanismos que fazem com que o BC seja mais comprometido na busca dos objetivos inflacionários. 
Tabela 2: Aspectos Operacionais de Metas Inflacionárias

\begin{tabular}{|c|c|c|c|}
\hline $\begin{array}{l}\text { País } \\
\text { (data da adoção) }\end{array}$ & Medida de Inflação & Meta (\% a.a.) & Horizonte \\
\hline $\begin{array}{l}\text { Austrália } \\
\text { (abril - 1993) }\end{array}$ & $\begin{array}{c}\text { IPC } \\
\text { (exclui: preços de frutas e } \\
\text { vegetais, } \\
\text { petróleo, taxa de juros, preços } \\
\text { controlados pelo setor público, } \\
\text { e outros preços voláteis) }\end{array}$ & 2 a 3 & indefinido \\
\hline $\begin{array}{l}\text { Brasil } \\
\text { (junho - 1999) }\end{array}$ & IPCA & $\begin{array}{l}8( \pm 2)-1999 \\
6( \pm 2)-2000 \\
4( \pm 2)-2001\end{array}$ & 1 ano \\
\hline $\begin{array}{l}\text { Canadá } \\
\text { (fevereiro - 1991) }\end{array}$ & $\begin{array}{c}\text { IPC } \\
\text { (exclui: alimentos, energia } \\
\text { e efeitos primários dos } \\
\text { impostos indiretos) }\end{array}$ & 1 a 3 & 18 meses \\
\hline $\begin{array}{l}\text { Finlândia } \\
\text { (fevereiro - 1993) }\end{array}$ & $\begin{array}{c}\text { IPC } \\
\text { (exclui: subsídios governamentais, } \\
\text { impostos indiretos, preços } \\
\text { de imóveis e pagamentos } \\
\text { de juros imobiliários) }\end{array}$ & em torno de 2 & 1 ano \\
\hline $\begin{array}{l}\text { Israel } \\
\text { (dezembro - 1991) }\end{array}$ & IPC & 8 a 11 & 1 ano \\
\hline $\begin{array}{l}\text { Nova Zelândia } \\
\text { (março - 1990) }\end{array}$ & $\begin{array}{c}\text { IPC } \\
\text { (exclui: variações em impostos } \\
\text { indiretos ou tarifas públicas, } \\
\text { variações significativas nos } \\
\text { termos de troca, taxa de juros } \\
\text { e desastres naturais) }\end{array}$ & $\begin{array}{c}0 \text { a } 2 \text { - até } \\
\text { novembro de 1996; } \\
0 \text { a } 3 \text { - a partir de } \\
\text { dezembro de } 1996\end{array}$ & 1 ano \\
\hline $\begin{array}{l}\text { Espanha } \\
\text { (janeiro - 1995) }\end{array}$ & $\begin{array}{c}\text { IPC } \\
\text { (exclui: efeitos primários } \\
\text { dos impostos indiretos) }\end{array}$ & abaixo de 3 & indefinido \\
\hline $\begin{array}{l}\text { Suécia } \\
\text { (janeiro - 1993) }\end{array}$ & IPC & $2 \pm 1$ & indefinido \\
\hline $\begin{array}{l}\text { Reino Unido } \\
\text { (outubro - 1992) }\end{array}$ & $\begin{array}{c}\text { RPIX - índice de vendas a varejo } \\
\text { (exclui: pagamentos de juros } \\
\text { imobiliários) }\end{array}$ & 2,5 ou menos & $\begin{array}{c}\text { Até o fim } \\
\text { do atual } \\
\text { Parlamento }\end{array}$ \\
\hline
\end{tabular}

Fontes: Bernanke \& Mishkin (1997, p. 99) e Banco Central do Brasil (1999).

Responsáveis pela política monetária em diversos países têm adotado metas inflacionárias (ver tabela 2) porque acreditam ter encontrado uma estrutura capaz de neutralizar as expectativas inflacionárias dos agentes sem estarem sujeitos aos problemas presentes em outros regimes. A idéia principal consiste no fato de que uma meta específica para a inflação representa uma âncora para as expectativas inflacionárias e aumenta a confiança na condução da política monetária de forma superior à adoção de uma meta para a taxa de câmbio ou para agregados monetá- 
rios, uma vez que problemas para a estabilidade de preços decorrente de ataques especulativos e instabilidade na velocidade da moeda são eliminados (Stevens \&

Debelle, 1995). Ademais, as metas inflacionárias aumentam a independência de instrumento do $\mathrm{BC}^{16}$, reduzindo o viés inflacionário ${ }^{17}$ na condução da política monetária. Esta é uma observação importante, pois indica a necessidade de ausência de dominância fiscal como pré-requisito para o sucesso do regime de metas inflacionárias, visto que a existência de elevados déficits fiscais pode provocar a monetização da dívida pública dando início a um processo de aceleração inflacionária (Mishkin \& Savastano, 2000).

Diferentemente do caso de fixação da taxa de câmbio, e da mesma forma que no caso de metas monetárias, a utilização de metas inflacionárias permite à política monetária responder a choques sobre a economia. Ademais, conserva a propriedade de ser facilmente compreendida pelo público. Outra vantagem atribuída às metas inflacionárias é que elas são capazes de atenuar os efeitos (positivos e negativos) oriundos de um choque de demanda, visto que são estabelecidos os limites superior e inferior para a flutuação da taxa de inflação (Bernanke \& Mishkin, 1997).

De forma diferente de simples regras políticas, as metas para a inflação permitem ao BC o uso de modelos de estrutura e decisão em conjunto com todas as informações relevantes para determinar a ação política mais adequada para obter a meta anunciada. Além disso, há dois elementos que afastam as metas inflacionárias da situação de uma regra rígida (Mishkin, 1999): i) metas de inflação não propiciam instruções simples e mecânicas de como o BC deveria conduzir a política monetária; e ii) metas para a inflação apresentam, tal como têm sido empregadas, elevado grau de discrição da política. Outrossim, há a vantagem adicional de que o regime em consideração possibilita o uso de políticas discricionárias sem levar à perda de credibilidade ${ }^{18}$. Ou seja, o regime de metas inflacionárias deve ser entendido como um caso em que há discrição limitada.

\footnotetext{
${ }^{16}$ Liberdade do banco central em fazer uso dos instrumentos necessários para que possa alcançar seus objetivos sem depender de nenhuma outra autoridade política.

${ }^{17} \mathrm{O}$ conceito de viés inflacionário deriva do argumento de ineficácia das políticas. O âmago do conceito pode ser entendido como a tentação que os governos têm de buscar um aumento do produto e/ou redução do nível de desemprego por meio do uso de políticas monetárias expansionistas. Em outras palavras, os governos são propensos a fazer uso do chamado princípio aceleracionista da curva de Phillips (versão Friedman-Phelps), cujo resultado de longo prazo seria apenas um aumento da taxa de inflação. Daí o termo viés inflacionário - má condução da política monetária que acarreta como único resultado maior inflação.

${ }^{18} \mathrm{Na}$ análise sobre metas inflacionárias, a credibilidade do regime é resultado da credibilidade operacional e da credibilidade política, isto é, "Operational credibility refers to ability of the central bank to fulfil the announced target of monetary policy and is, of course, affected by the conduct of monetary policy. (...) A different concept is political credibility, which reflects investors' assessment about the probability of a regime shift, where the present price-stability target is given up, at least temporarily. Political credibility depends to a large extent on the political support for the price-stability target, and to a lesser extent on the conduct of monetary policy" (Andersson \& Berg, 1995, p. 214, grifos meus).
} 
$\mathrm{Na}$ tentativa de evitar a manifestação de um possível dilema entre credibilidade e flexibilidade, a solução encontrada tem sido a estratégia de misturar uma regra simples com a discrição, isto é, o anúncio de uma meta para a inflação com a presença de cláusulas de escape ${ }^{19}$. De outra forma, em condições normais, o BC segue a meta anunciada e se desvia dela apenas no caso em que ocorrem grandes choques sobre o produto. A vantagem dessa estrutura é que o uso de cláusulas de escape em situações extremas não implica perda de credibilidade quando a meta não é obtida, pois a mudança na política planejada não é resultado da adoção de políticas inconsistentes no tempo, mas resultado de variáveis que não podem ser mensuradas ${ }^{20}$.

Na prática, a regra política antiinflacionária mais utilizada tem sido o anúncio de bandas para a inflação. Uma banda mais larga implica maior flexibilidade e maior probabilidade da meta ser alcançada. O problema com essa estrutura é que ela não oferece um bom guia para a formação de expectativas. Se houver falta de credibilidade, o público incorpora às expectativas o limite superior da banda, o que implica mais tempo para o processo de busca da estabilidade de preços. Uma outra possibilidade consiste no anúncio de um único número com a presença de cláusulas de escape.

A distinção entre a adoção de bandas ou de um único ponto tem importância secundária caso os agentes sejam dotados de expectativas racionais. A razão para essa interpretação baseia-se no argumento de que os agentes sabem que as autoridades monetárias possuem capacidade limitada na determinação da taxa de inflação. Destarte, mesmo que seja anunciado um ponto como meta, as expectativas serão formadas para uma taxa de inflação próxima à anunciada. A vantagem da utilização de bandas é que a transparência é maior e pequenas flutuações na taxa de inflação não precisam ser justificadas aos agentes (Brunilla \& Lahdenperä, 1995).

$\mathrm{Na}$ análise sobre o regime de metas inflacionárias existe o debate sobre qual a melhor meta a ser adotada: taxa de inflação ou nível de preços ${ }^{21}$. Uma desvantagem relativa para a adoção da taxa de inflação como meta é que não há resposta para choques não-antecipados sobre o nível de preços. Sendo assim, previsões para inflação que envolvam um espaço de tempo longo devem apresentar variância elevada, tendo por resultado uma redução na capacidade de planejamento do setor privado. Por outro lado, uma meta para o nível de preços requer que overshoots e

\footnotetext{
${ }^{19}$ Em geral, as cláusulas de escape têm sido utilizadas para excluir os efeitos decorrentes de importantes choques de oferta, tais como: mudanças nos termos do comércio; mudanças nos impostos indiretos; desastres naturais; encargos governamentais, e taxas de juros.

${ }^{20}$ Deve-se ressaltar que as cláusulas de escape não representam uma solução para os problemas advindos da incerteza sobre as previsões da inflação. Em última instância, o sucesso das metas depende da acuidade da previsão inflacionária.

${ }^{21}$ Para uma leitura sobre essa controvérsia, ver Yates (1995), Haldane \& Salmon (1995), e Andersson \& Berg (1995).
} 
undershoots da meta sejam eliminados por completo, o que acarreta menor variância nos modelos de previsão de preços de longo termo 22 .

Todos os países que optaram pelo regime de metas inflacionárias têm adotado como meta uma inflação maior que zero (ver tabela 2). Essa postura deriva do argumento de que a existência de uma inflação baixa não gera problemas de expectativas sobre a taxa de inflação futura ou problemas de credibilidade para o BC. Ademais, é admitido que uma taxa de inflação próxima a zero provocaria uma pressão permanente para o aumento da taxa natural de desemprego acarretando problemas de natureza recessiva para a economia.

Ainda que o controle da inflação seja considerado o objetivo prioritário da política monetária, não pode ser negado que os bancos centrais possuem objetivos de curto prazo, sobretudo no que se refere ao produto e a taxa de câmbio. Essa é uma observação importante, pois podem ser gerados problemas que reduzem a acuidade da autoridade monetária na obtenção das metas planejadas. Não obstante, é importante salientar que a presença do produto na função objetivo da autoridade monetária não significa que haverá a manifestação do viés inflacionário; é necessário apenas que a meta atribuída ao produto seja equivalente ao produto potencial.

Um dos principais argumentos favoráveis à adoção de metas inflacionárias refere-se ao aumento da transparência na condução da política monetária ${ }^{23}$. $\mathrm{Na}$ maioria dos países que utilizam o sistema de metas para a inflação, a transparência é reforçada pelo aumento da comunicação entre a autoridade monetária e o público. Essa comunicação é feita, em grande parte, por meio de relatórios de inflação. Tais relatórios apresentam quatro pontos básicos (Mishkin, 1999): i) as metas e os limites da política monetária; ii) os valores numéricos da meta de inflação e como eles foram determinados; iii) como as metas para a inflação são obtidas, dadas as condições atuais da economia; e iv) as razões para os possíveis desvios das metas anunciadas.

Os benefícios provenientes de uma maior transparência podem ser entendidos pelo seguinte esquema de delegação eficiente da política monetária em uma sociedade democrática:

“(...) (1) society (the collective of the citizens) announces goals for monetary policy, (2) the central bank receives instrument independence to pursue the goals without short-term political inference, and (3) the central bank is accountable to society for fulfilling the goals. Transparency of the

\footnotetext{
${ }^{22}$ Apesar desse resultado parecer razoável, é importante lembrar que esse tipo de conduta pode levar a uma política monetária mais volátil no curto prazo.

${ }^{23} \mathrm{O}$ caso mais formalizado para a transparência das ações do banco central é o da Nova Zelândia. Nesse país, o governo tem o direito de demitir o presidente do banco central caso a inflação se desvie em $25 \%$ da taxa anunciada. Exemplo de benefícios oriundos de maior transparência das ações do banco central podem ser ilustrados com os casos de Canadá (1996) e Inglaterra (1997). Para uma análise detalhada sobre esses países, ver Mishkin \& Posen (1997).
} 
goals and the policy is then crucial for the accountability of the central bank, that is, for society's monitoring and evaluation of monetary policy. Transparency thus improves the central bank's incentives to pursue the announced goals. Transparency may also facilitate public understanding of monetary policy and make monetary policy more predictive, which may stabilize inflation expectations and increase the credibility of monetary policy. Improved public understanding and increased credibility is likely to facilitate the implementation of monetary policy and thereby contribute to the achievement of the goals." (Svensson, 1999, p. 39, grifo meu)

Apesar do argumento de que metas inflacionárias são capazes de aumentar a transparência e reduzir o viés inflacionário da política monetária, deve-se lembrar que o regime sobredito permite a ação discricionária do BC, o que, por sua vez, não elimina por completo o viés inflacionário (Herrendorf, 1998). Portanto, o uso desse regime por si só não significa que o $\mathrm{BC}$ seja sempre avesso à inflação. $\mathrm{O}$ benefício que pode ser obtido pelo anúncio de uma meta inflacionária explícita é que, se ela for crível, pode induzir os agentes a refazerem suas expectativas fazendo com que elas convirjam de forma rápida para a meta anunciada.

A principal dúvida que tem sido colocada no debate sobre a implementação de metas inflacionárias é se a inflação é previsível e controlável o bastante para receber uma meta. A dificuldade em prever a inflação de forma precisa para períodos muito curtos e longos implica dois problemas potenciais para a estratégia de metas inflacionárias ${ }^{24}$ : i) problema de natureza operacional — uma vez que há um hiato temporal entre a ação da política monetária e a resposta da inflação, isso implica baixa previsibilidade, o que pode resultar em problemas de precisão para a meta; e ii) credibilidade do $\mathrm{BC}$ - como a inflação apresenta alto grau de imprevisibilidade, há dificuldade no julgamento do público em avaliar o esforço realizado pelo BC para a obtenção da meta anunciada (Bernanke \& Mishkin, 1997).

Os dois pontos acima merecem comentários adicionais. O primeiro item remete à questão operacional da política monetária. Deve-se lembrar que a política é executada no curto prazo, e que o mundo real é dinâmico. Portanto, trabalhar com soluções que correspondem à situação de estado estacionário é útil apenas para análise no universo teórico. O segundo ponto vai ao encontro da idéia de que um regime de metas inflacionárias aumenta a compreensão da política monetária, além disso, sugere que a construção de credibilidade por meio desse regime pode ser um árduo e longo processo.

\footnotetext{
${ }^{24}$ Deve-se ressaltar que a ausência de bons modelos estruturais para a previsão da inflação e o fato das previsões geradas pelo VAR serem razoáveis apenas para o caso de economias que se encontram numa situação de equilíbrio estacionário pode acarretar dificuldades para a aplicação das metas inflacionárias. Como grande parte das economias utiliza o regime de metas inflacionárias na tentativa de conquistar credibilidade e garantir baixas taxas de inflação, isso sugere que não é comum as economias estarem na situação de estado estacionário, e, portanto, as previsões geradas pelo modelo macroeconométrico de auto-regressão vetorial tendem a não ser confiáveis.
} 
Uma outra observação diz respeito à utilização de metas para a inflação em economias que apresentam elevado (ou parcial) grau de dolarização da economia. Esse é um problema em especial para países da América Latina, onde a maior parte da dívida de longo prazo é denominada em dólar. Como o regime de metas inflacionárias requer uma taxa de câmbio flexível, e ainda pelo fato de as economias da região possuírem elevada abertura, e por serem dependentes de financiamento externo, choques sobre a taxa de câmbio são inevitáveis. Assim, grandes e abruptas depreciações provocam um aumento substancial do passivo denominado em dólar, aumentando o risco de uma crise financeira. Portanto, o uso de metas inflacionárias em economias com algum nível de dolarização somente será viável se existir uma regulação prudente e rigorosa das instituições financeiras de forma que seja assegurada a capacidade de resistir a choques sobre a taxa de câmbio (Mishkin \& Savastano, 2000).

\section{CONCLUSÕES}

A análise realizada permite observar que os três regimes monetários em questão possuem (de forma diferenciada) a capacidade de influenciar o comportamento dos preços de uma economia. Apesar das vantagens e desvantagens peculiares a cada regime (ver apêndice), observa-se que todas as estruturas têm como elemento comum a preocupação em reduzir o problema de inconsistência temporal associado à condução da política monetária. Esse resultado sugere que o principal elemento capaz de desencadear um processo inflacionário não se concentra nos choques, mas no mau gerenciamento da política monetária. Ou seja, é necessário desenvolver mecanismos que sejam capazes de levar a economia para os resultados planejados.

As estratégias apresentadas para a política monetária podem ser entendidas como um caso da aplicação de regras, o que, por conseguinte, apresenta as desvantagens inerentes à sua prática. Esse é um problema comum quando são empregadas metas para a taxa de câmbio e para agregados monetários. Por outro lado, o regime de metas para a inflação representa um avanço para contornar o problema. As metas inflacionárias podem ser entendidas como uma situação em que há discrição limitada, isto é, o anúncio de uma meta é uma característica da utilização de regra, todavia, também está presente o elemento discricionário, visto que o $\mathrm{BC}$ tem liberdade na condução da política monetária para a consecução da meta anunciada.

Ainda que as metas para a inflação sinalizem um desempenho superior ao uso de metas para câmbio e agregados monetários, o tipo de discussão apresentado não tem a possibilidade de apresentar qual o melhor tipo de regime monetário. O regime a ser escolhido por um país depende em grande medida do cenário macroeconômico em que está inserido. Além disso, verifica-se que todas as estratégias estudadas apresentam problemas na capacidade da política monetária de atingir de forma isolada os objetivos pretendidos. Destarte, uma idéia que não deve ser desprezada quando se busca o melhor arranjo entre metas e instrumentos é o argumento keynesiano da coordenação de políticas econômicas. 


\section{REFERÊNCIAS BIBLIOGRÁFICAS}

ANDERSSON, K. \& BERG, C. “The Inflation Target in Sweden”. In: Haldane, A.G. (org.) Targeting Inflation. Bank of England, 1995.

ASCHHEIM, J. \& TAVLAS, G. S. "Nominal Anchors for Monetary Policy: A Doctrinal Analysis”. BNL Quarterly Review 191, December 1994.

BANCO CENTRAL DO BRASIL. Relatório de Inflação, junho de 1999.

BARRO, R. J. “Money and the Price Level Under the Gold Standard”. Economic Journal 89, March 1993. BERNANKE, B. \& MISHKIN, F. “Inflation Targeting: A New Framework for Monetary Policy?”. Journal of Economic Perspectives, vol. 11(2), Spring 1997.

BORDO, M. "The Gold Standard, Bretton Woods and Other Monetary Regimes: a Historical Appraisal”. Federal Reserve Bank of St. Louis, March/April 1993.

BRUNILLA, A. \& LAHDENPERÄ, H. "Inflation-targets: Principal Issues and Practical Implementation". In: Haldane, A. G. (org.) Targeting Inflation. Bank of England, 1995.

CECCHETTI, S. \& EHRMANN, M. "Does Inflation Targeting Increase Output Volatility? An International Comparison of Policymakers' Preferences and Outcomes". NBER Working Paper Series 7426, December 1999.

CLARIDA, R., GALI, J. \& GERTLER, M. “The Science of Monetary Policy: A New Keynesian Perspective”. NBER Working Paper 7147, May 1999.

EUROPEAN MONETARY INSTITUTE. "The Single Monetary Policy in Stage Three: Elements of the Monetary Policy Strategy in the ESCB", European Monetary Institute.

EVANS, C.L. \& KUTTNER, K.N. “Can VARs Describe Monetary Policy?” Mimeo, 1998.

HALDANE, A. \& SALMON, C. “Three Issues on Inflation-target Framework”. In: Haldane, A. G. (org.) Targeting Inflation. Bank of England, 1995.

HERRENDORF, B. "Inflation Targeting as a Way of Precommitment". Oxford Economic Papers, vol. 50, n. 3, July 1998.

KEYNES, J.M. Essays in Persuasion. New York: The Norton Library, 1963.

. A Tract on Monetary Reform. The Collected Writtings of John Maynard Keynes. London: MacMillan, 1971.

KOPCKE, R. W. "Currency Boards: Once and Future Monetary Regimes?”. New England Economic Review, Federal Reserve Bank of Boston, May-June 1999.

MARSHALL, A. "Remedies for Fluctation in General Prices". The Contemporary Review, 1887.

McCALLUM, B. T. "Recent Developments in Monetary Policy Analysis: the roles of theory an evidence". NBER Working Paper 7088, April 1999.

MENDONÇA, H.F. “A Teoria da Independência do Banco Central: Uma Interpretação Crítica”. Estudos Econômicos, Instituto de Pesquisas Econômicas — USP, São Paulo, vol. 30, n. 1, 2000.

"Metas Inflacionárias: uma reflexão”. Gazeta Mercantil, n. 503, 26 de janeiro de 2000. . "Regimes Monetários e o Brasil". Gazeta Mercantil, n. 453, 12 de novembro de 1999.

MISHKIN, F. “International Experiences with Different Monetary Policy Regimes”. NBER Working Paper 6965, February 1999.

MISHKIN, F. \& POSEN, A. “Inflation Targeting: Lessons from Four Countries”. Federal Reserve Bank of New York. Economic Policy Review, vol. 3, n. 3, August 1997.

MISHKIN, F. \& SAVASTANO, M. A. “Monetary Policy Strategies for Latin America”. NBER, Draft: February 22, 2000.

SCHWARTZ, A. J. "Alternative Monetary Regimes: the Gold Standard”. In: SCHWARTZ, A. (org.), Money in Historical Perspective. Chicago: The University of Chicago Press, 1987.

STEVENS, G \& DEBELLE, G. “Monetary Policy Goals for Inflation of Australia”. In: Haldane, A. G. (org.) Targeting Inflation. Bank of England, 1995.

SVENSSON, L. “Monetary Policy Issues for the Eurosystem”. NBER Working Paper 7177, June 1999. WICKSELL, K. Interest and Prices. London: Macmillan, 1898.

YATES, A. “On the Design of Inflation-target Framework”. In: Haldane, A. G. (org.) Targeting Inflation. Bank of England, 1995. 


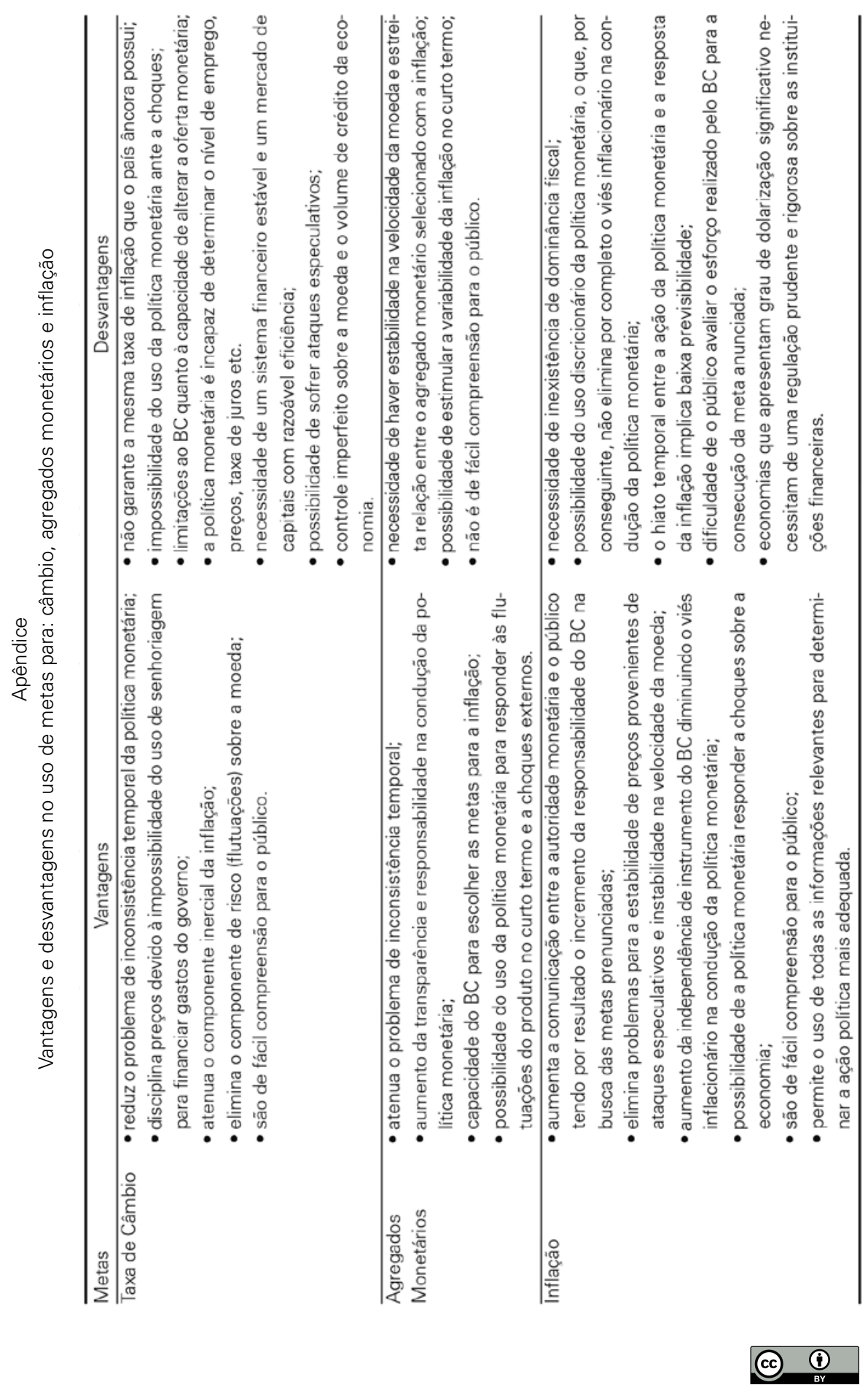

